\title{
Contribution of the Pressure Moments to the Interpretation of Numerical Simulations of Well Tests
}

\author{
BLANC, Georges, Institut Français du Pétrole \\ NETINGER, Benoit, Institut Français du Pétrole \\ PIACENTINO, Laurent, BEICIP-FRANLAB \\ and HÉLIOS Reservoir Group
}

Paper presented at the 5th European Conference on the Mathematics of Oil Recovery, Leoben, Austria, 3-6 Sept. 1996

\begin{abstract}
Numerical simulation of well tests in complex reservoirs is a tool which adds to the conventional analytical interpretation methods.
\end{abstract}

Generally speaking, the interpretation of a well test is made easy when one can relate the well pressure behaviour to the petrophysical properties of the area investigated by the test. Identification of the investigation area is a rather difficult task when the local diffusivity variation is large. This paper shows how the computation of the area of investigation can be achieved using the moments of the spatial pressure variations.

After a validation of the proposed derivation in simple cases, the methodology is applied to a fully heterogeneous reservoir built with a geostatistical simulation program. A method to compute the average permeability within the computed investigation area is proposed. Such permeability is in good agreement with the apparent permeability derived from the pressure derivative of the simulated test.

When DST are simulated, the rate effect on the spatial pressure variations must be first eliminated before using the previous results. A solution to this problem is also provided in this paper.

\section{INTRODUCTION}

The geostatistical modelling of reservoir deposits is now widely used by geoscience engineers to complete reservoir simulation grids. These models, made up of facies pixels or geologic objects, reflect the main statistics of the geological environment.

Well tests results are of paramount importance in the verification of the validity of such models, as is the simulation of these tests. Analytical solution methods no longer provide the well-test pressure behaviour in such complex situations and so that numerical simulation program must be used instead.

From a general standpoint, the well test analysis is facilitated when the user can relate the changes in the shape of the pressure derivative curve to a change in the reservoir properties at a known distance from the well. This points out how important the knowledge of the investigation radius is.

The problem of determining the investigation radius in a homogeneous reservoir throughout well tests has been discussed by several works in the past, as in the paper presented by H.K. Van Poolen'. From among them we will retain the definition proposed by J. $\mathrm{Lee}^{2}$ and $\mathrm{M}$. Muskat ${ }^{3}$, which defines the investigation radius as the distance from the well where the pressure change is fastest. This definition is useful for well test interpretation because the corresponding time shows the influence of a reservoir heterogeneity located at the corresponding investigation radius.

When heterogeneous formations are considered, the work presented by $B$. Nœtinger ${ }^{4}$ relies on the investigation radius for the analysis of the moments of pressure drawdown all over the reservoir. The method proposed in this work, well suited to the analysis of numerical simulation results, has been extended and is the basis of the present paper.

\section{MOMENTS OF THE PRESSURE VARIATION}

\section{Numerical Well Test Simulation}

The pressure behaviour of a single-phase flow in a 3D reservoir is governed by the following equation:

$$
\frac{\partial}{\partial x_{i}}\left(\frac{k_{i}}{\mu} \frac{\partial(P+\rho g z)}{\partial x_{i}}\right)=\phi c_{t} \frac{\partial P}{\partial t}+q
$$


where :

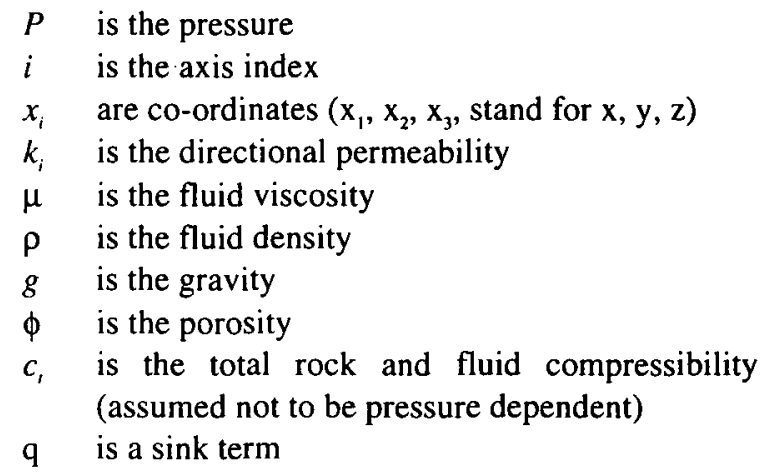

Analytical solution methods no longer provide the well-test pressure behaviour when the geometry of the reservoir is complicated or when the reservoir is heterogeneous. In these cases numerical simulation must be used.

The simulation program ${ }^{5}$ used for numerical well test simulation is based on the 7-point finite-difference scheme of Equation (1). The grid-block system is Cartesian irregular (Figure 1) and dead cells are used to simulate complex shapes.

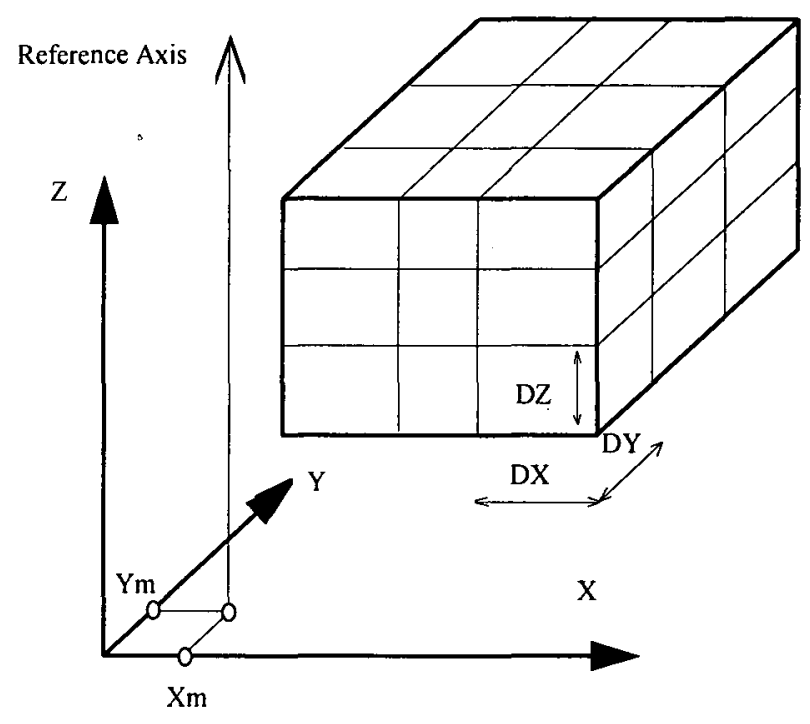

Figure 1 - Grid block system

Discretisation of Equation (1) in space and time, for a grid-block $i$ and at time $\operatorname{step} n$, is:

$\sum_{j} \frac{T_{i j}}{\mu}\left[\left(P_{j}^{n}-P_{i}^{n}\right)+\rho g\left(z_{j}-z_{i}\right)\right]=$

$\phi c_{1} V i \frac{P_{i}^{n}-P_{i}^{n-1}}{t^{n}-t^{n-1}}+\delta_{i p} Q_{p}$

where:

$j \quad$ is the index of all neighbours of grid-block $i$

$T_{i j} \quad$ is the transmissivity between grid-blocks $i$ and $j$ (harmonic average of $h \times k$ products)
$V_{i} \quad$ is the volume of grid-block $i=D X_{i} \times D Y \times D Z_{i}$

$Q_{p}$ is the rate of the well $p$

$\delta_{i p}$ is equal to 1 when grid-block $i$ contains well $\mathrm{p}$ and 0 elsewhere

$P^{n}$, is then the solution vector to the following matrix equation:

$A^{n} \times P^{n}=B^{n}$

where:

$A^{n}$ is the 7-band matrix of the system of discretised equations at time $n$

$P^{n} \quad$ is the vector of the pressure map at time $n$

$B^{n} \quad$ is the vector column of the right hand side of the system of discretised equations at time $n$

\section{Moments of the Pressure Drawdown}

In this paper we will only consider the analysis of vertical wells. This will restrict the following developments to the definition of the moments of the pressure drawdown with reference to a vertical axis (Figure 1).

Let us define the following terms :

- the vector of the horizontal distance from the centre of a grid block $i$ to the reference axis, denoted $\vec{r}$ :

$$
\vec{r}=\vec{r}_{i}=\left[\begin{array}{l}
r_{x} \\
r_{y} \\
r_{z}
\end{array}\right]=\left[\begin{array}{l}
X_{i}-X_{m} \\
Y_{i}-Y_{m} \\
Z_{i}
\end{array}\right]
$$

- the pressure drawdown at distance $r$ and at any given time $t$ from the beginning of the test :

$$
\partial P(\vec{r}, t)=P(\vec{r}, t)-P(\vec{r}, t=0)
$$

The first 3 moments, $M_{o}, M_{1}$ and $M_{2}$, of the pressure drawdown are defined as follows :

$$
M_{0}(t)=\int_{\text {res. }} \partial P(\bar{r}, t) \times \phi(\vec{r}) \times C_{t}(\vec{r}) \times d \vec{r}
$$

$M_{o}(t)$ is a scalar with dimension $\left[\mathrm{M}^{3}\right]$.

$$
M_{1}(t)=\int_{\text {res. }}\left[\begin{array}{l}
r_{x} \\
r_{y}
\end{array}\right] \times \partial P(\bar{r}, t) \times \phi(\vec{r}) \times C_{t}(\vec{r}) \times d \vec{r}
$$

$M_{1}(t)$ is a vector $\left[\begin{array}{l}M_{1 x}(t) \\ M_{1 y}(t)\end{array}\right]$. The dimension of each component is $\left[\mathrm{M}^{4}\right]$.

$$
M_{2}(t)=\iint_{r e s .}\left[\begin{array}{rr}
r_{x}^{2} & r_{x y} \\
r_{x y} & \cdot r_{y}^{2}
\end{array}\right] \times \partial P(\bar{r}, t) \times \phi(\vec{r}) \times C_{t}(\vec{r}) \times d \bar{r}(7)
$$


$M_{2}(t)$ is a tensor $\left[\begin{array}{ll}M_{2 x}(t) & M_{2 x y}(t) \\ M_{2 x y}(t) & M_{2 y}(t)\end{array}\right]$. The dimension of each component is $\left[\mathrm{M}^{5}\right]$.

Each of these 7 components can be simply evaluated at any given simulation time from the pressure field $P^{n}$. Note that the vertical axis is in fact the well axis.

\section{Normalised Moments of the Pressure Drawdown}

For the interpretation of the pressure moments, the components are normalised as follows :

$m 0(t)=M 0(t)$

$m 1 x(t)=\frac{M 1 x(t)}{M 0(t)}$ and $m 1_{y}(t)=\frac{M 1 y(t)}{M 0(t)}$

The dimension of the above two components is [M].

$m 2 x(t)=\frac{M 2 x(t)}{M 0 x(t)}-m 1 x(t)^{2}$

$m 2 y(t)=\frac{M 2 y(t)}{M 0 x(t)}-m 1 y(t)^{2}$

$m 2 x y(t)=\frac{M 2 x y(t)}{M 0 x(t)}-m 1 x(t) \times m 1 y(t)$

The dimension of the above three components is $\left[\mathrm{M}^{2}\right]$.

\section{INTERPRETATION OF THE MOMENTS}

\section{Basic interpretation}

B. Nætinger ${ }^{4}$ gave an interpretation of the first three moments under the following conditions :

- The reservoir is homogeneous : the permeability, the porosity, the total compressibility and the thickness are constant everywhere ;

- The well-rate is constant and the reservoir is closed (no lateral alimentation) ;

- The duration of the test is short enough so the reservoir boundaries do not affect the well pressure.

Under these conditions, the iso-pressure drawdown curves are circular with centres located at the well location.

When the previous conditions apply, the first three moments can be interpreted as follows :

- The zero-order moment is clearly equal to the volume liberated by compressibility expansion of the reservoir. This volume is the cumulative volume produced at the well sand face during the test :

$$
m 0(t)=\int_{0}^{t} Q s f(t) \times d t
$$

- All the components of the first order moment are equal to 0 :

$$
m(t)=m 1 x(t)=m 1 y(t)=0
$$

- The components of the second order moment are:

$$
\begin{aligned}
& m_{2 x y}(t)=0 \\
& m_{2 x}(t)=m_{2 y}(t)=\frac{k}{\phi \mu C_{t}} t=\eta \times t
\end{aligned}
$$

$\eta$ is the reservoir diffusivity

If we introduce the investigation radius $R_{i n v}$ as defined by J. Lee ${ }^{2}$ and M. Muskat ${ }^{3}$, the equation (16) leads to :

$$
m_{2}(t) / 2=m_{2 x}=m_{2 y}=R_{i n v}^{2}
$$

In B. Notinger's paper a validation of the relationship (17) is given which shows that the permeability $\mathrm{k}$ can be derived from the interpretation of the second order moment of the pressure drawdown.

\section{Extended interpretation}

The previous interpretation of the moments was extended to anisotropy pressure drawdown distributions. The first and second order moments could then be used to compute the geometric properties of an ellipse rather than a circle as in the previous interpretation (Figure 2). These properties are computed as follows:

- The co-ordinates of the centre of gravity of the ellipse are simply equal to the components of the first order moment :

$C_{x}(t)=m_{l x}(t)$ and $C_{y}(t)=m_{2 y}(t)$

- The main radii $R_{l}(t)$ and $R_{2}(t)$ of the ellipse are the solutions to the following equations :

$$
\begin{aligned}
& R^{4}+a \times R^{2}+b=0 \\
& a=-\left(m_{2 x}(t)+m_{2 y}(t)\right) \\
& b=m_{2 x}(t) \times m_{2 y}(t)-m_{2 x y}^{2}
\end{aligned}
$$

and the angle $\alpha(t)$ between $O x$ and $R_{1}$ is given by:

$$
\tan (a(t))=\frac{m 2 x(t)-R_{1}(t)}{-m 2 x y(t)}
$$




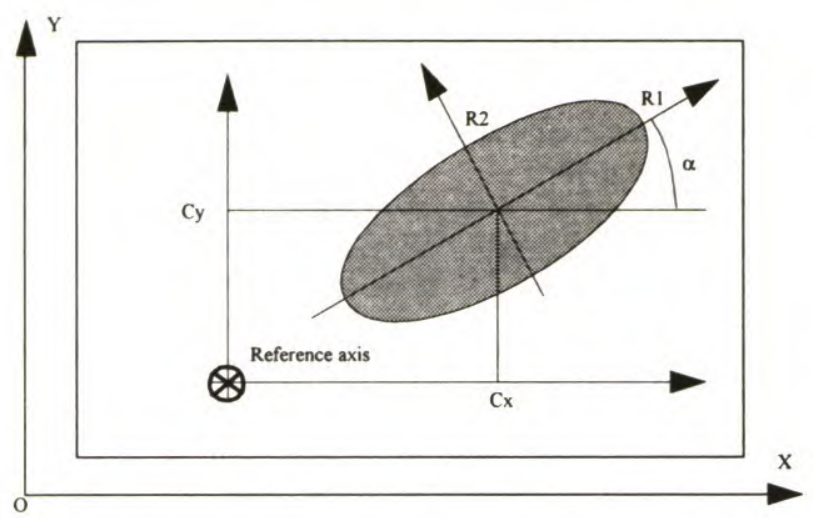

Figure 2 - Schematic representation of pressure drawdown

On one hand this generalisation provides the user of the numerical simulator with a schematic representation of the pressure drawdown. On the other hand, the radii $R_{l}(t)$ and $R_{2}(t)$ can be interpreted as equivalent reservoir directional drainage radii.

\section{VALIDATION}

Three validation examples are presented here. The first two check the validity of the formulas previously presented. The last example demonstrates the derivation of a permeability-time law from the pressure drawdown map and how this interpretation compares with the one that is based on the derivative interpretation.

\section{Example 1 - STRIP Models}

The STRIP Models are used to check the validity of the computation of the ellipses of the pressure drawdown (equations (18), (19) and (20)).

Two STRIP Models were used (Figure 3). These two models have the same dimensions and the same petrophysical properties except for their orientation (STRIP V is a vertical strip with its main axis parallel to the Oy axis and STRIP S has its main axis at $20^{\circ}$ to this Oy axis). The main characteristics of the two STRIP Models are shown in Table 1.

A synthetic drawdown constant rate test of $100 \mathrm{~h}$ was simulated on both models.

Figures 4 and 5 summarise the results of the simulations. They shows that the ellipses of the two models are the same during the test.

\begin{tabular}{|l|r|}
\hline \multicolumn{2}{|c|}{ Table 1 - STRIP Models - Main properties } \\
\hline RESERVOIR SHAPE properties \\
One layer 20 m thick \\
Rectangular Size (m) & $320 \times 3000$ \\
\hline ROCK properties & 700 \\
Permeability (mD) & 0.30 \\
Porosity (Fraction) & 20 \\
Thickness (m) & 0.5 \\
\hline FLUID properties & 1.0 \\
Fluid viscosity (cp) & \\
Volume Factor (m ${ }^{3}$ st/m ${ }^{3}$ ) & 8.0 \\
\hline Total Compressibility & 0.0 \\
Fluids+Rocks (bar ${ }^{-1}$ ) & \\
\hline WELL properties & $25 \times 43 \times 1$ \\
Weli radius (cm) & $83 \times 111 \times 1$ \\
Skin & \\
\hline NUMrRICAL MODELS properties & \\
Grid blocks STRIP V model & \\
Grid blocks STRIP S model & \\
\hline
\end{tabular}

At the end of the test, the $R_{1}$ radius stabilised at an upper limit of about $92 \mathrm{~m}$ that represents .575 of the half width of the strip. This clearly shows a limitation in the use of such ellipses to represent investigation areas when boundaries are reached by pressure drawdown surfaces. Such a limitation also applies to well test pressure interpretation when boundary effects are present. Nonetheless, the ellipse is still a good representation of the inertia of the pressure drawdown. It can easily be demonstrated that, when lateral boundaries are reached by the pressure drawdown surface, a channel-like flow regime occurs in the $\mathrm{Oy}$ direction. The pressure drawdown surface reduces to $1 \mathrm{D}$, and the relationship (5) lead to :

$$
R_{1}(t=\infty) / 160=1 / \sqrt{ } 3=0.577
$$

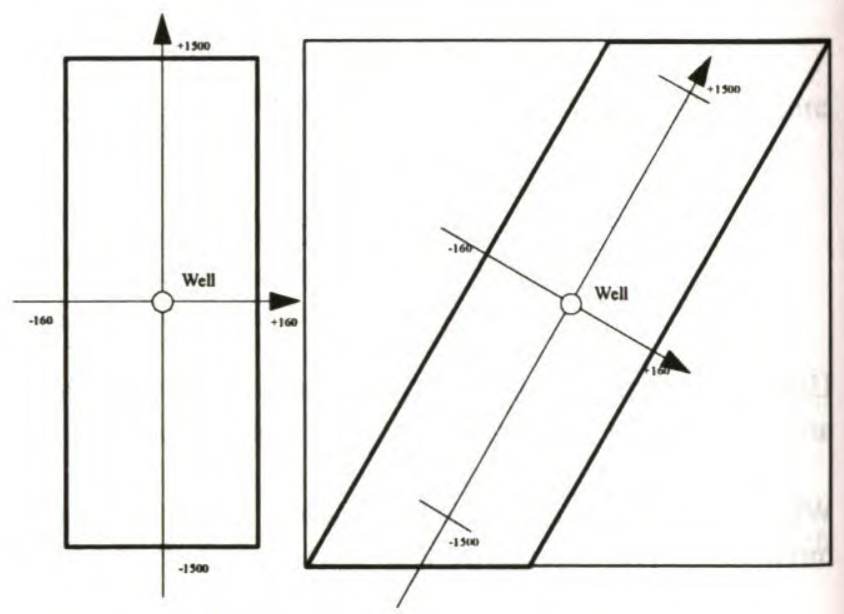

Figure 3 - STRIP Models 


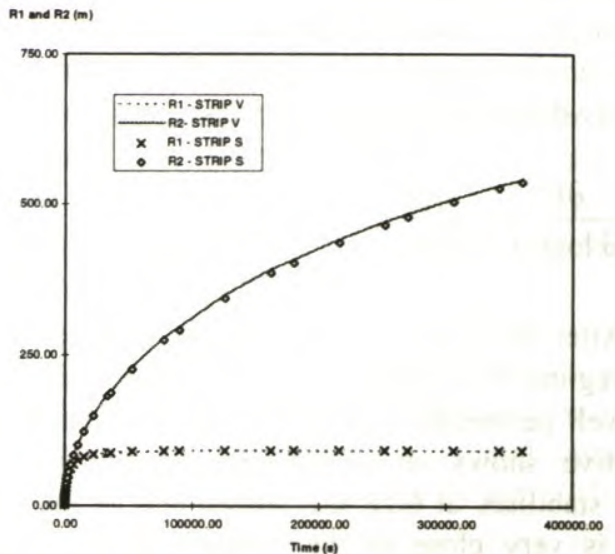

Figure 4 - STRIP Models - Evolution of R1 and R2 radii
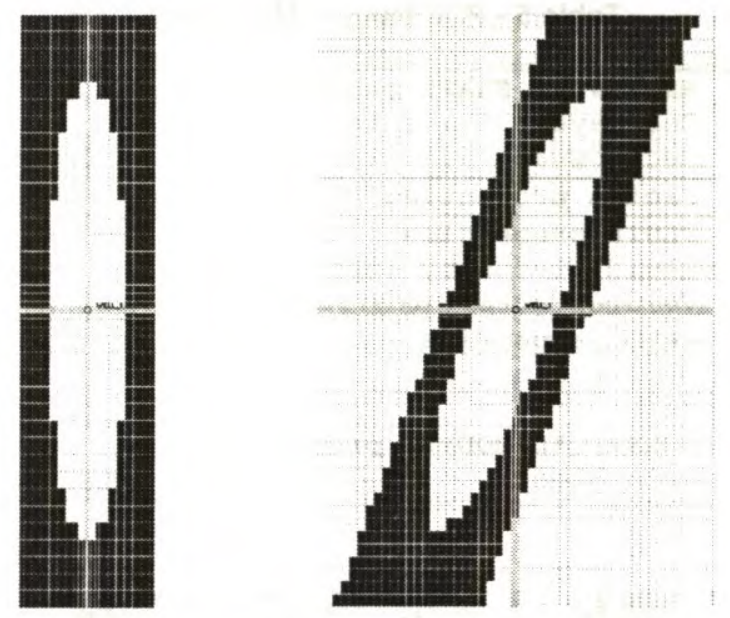

Figure 5 - STRIP Models - Location of ellipses after 100 hours

\section{Example 2 - DST model}

The DST model is a one layer rectangular reservoir as represented in Figure 6. It was built to illustrate a typical problem associated with the analysis of multiple rate tests.

The well rate history is made of 6 flow periods 39.85 hours long followed by one build-up period of 60 hours (Figure 7). The characteristics of the model are the same as those of the STRIP models (Table 4), except the well is not centred in the reservoir as shown in Figure 6, it is located $130 \mathrm{~m}$ from the left hand border.

\begin{tabular}{|c|c|}
\hline \multicolumn{2}{|c|}{ Table 2 - DST Model - Main properties } \\
\hline $\begin{array}{l}\text { RESERVOIR SHAPE properties } \\
\text { One layer } 10 \mathrm{~m} \text { thick } \\
\text { Rectangular Size (m) }\end{array}$ & $320 \times 3000$ \\
\hline $\begin{array}{l}\text { ROCK properties } \\
\text { Permeability (mD) } \\
\text { Porosity (Fraction) } \\
\text { Thickness (m) }\end{array}$ & $\begin{array}{r}700 \\
0.30 \\
18 \\
\end{array}$ \\
\hline $\begin{array}{l}\text { FLUID properties } \\
\text { Fluid viscosity ( } \mathrm{cp}) \\
\text { Volume Factor }\left(\mathrm{m}^{3} \mathrm{st} / \mathrm{m}^{3}\right)\end{array}$ & $\begin{array}{r}0.41 \\
1.0\end{array}$ \\
\hline $\begin{array}{l}\text { Total Compressibility } \\
\text { Fluids+Rocks }\left(\text { bar }^{-1}\right)\end{array}$ & $5.52 e-4$ \\
\hline $\begin{array}{l}\text { WELL properties } \\
\text { Well radius }(\mathrm{cm}) \\
\text { Skin }\end{array}$ & $\begin{array}{l}7.85 \\
-1.6\end{array}$ \\
\hline $\begin{array}{l}\text { NUMERICAL MODELS propertie } \\
\text { Grid blocks }\end{array}$ & $22 \times 79 \times 1$ \\
\hline
\end{tabular}

Table 3 and Figure 7 summarise the results of the DST simulation. It is shown that the centres of the ellipses migrate along the Ox axis toward the centre of gravity of the reservoir as expected. Also the $R_{1}$ radius stabilises at $92.2 \mathrm{~m}$ as did the STRIP models. Also the $R_{2}$ radius lengthens continuously throughout the flow periods. Actually this last fact demonstrates that this radius cannot be used to interpret any flow period of a DST but only the first one, as the rate effect are convoluted together. This point will be elaborated in the last paragraph of the paper.

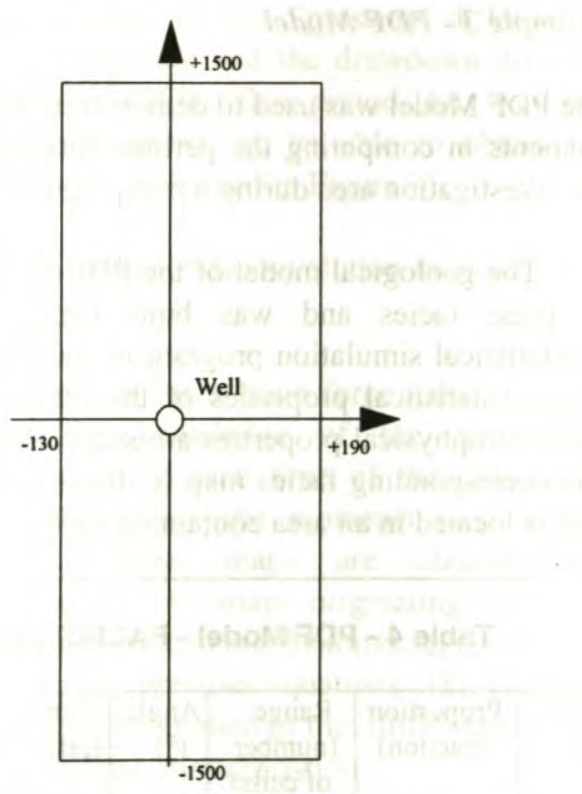

Figure 6 - DST Model 


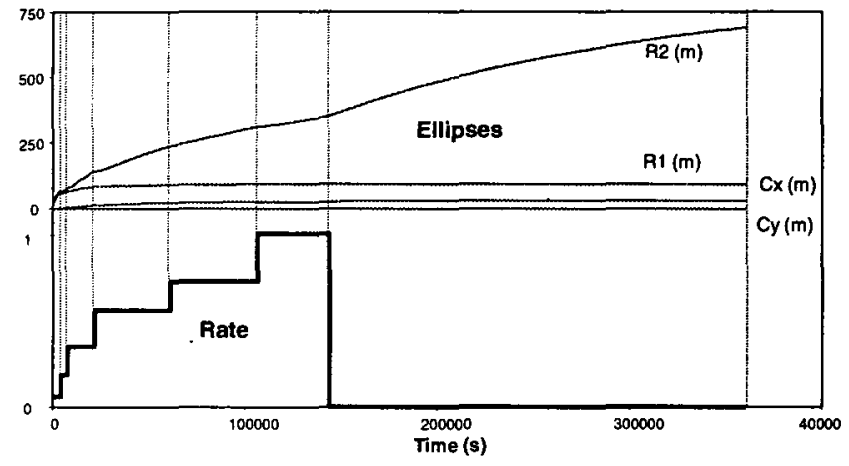

Figure 7- DST Model - Ellipse properties versus time

\begin{tabular}{|c|c|c|c|c|c|c|}
\hline \multicolumn{7}{|c|}{ Table 3 - DST Model - Main results } \\
\hline $\begin{array}{c}\text { Time } \\
(\mathbf{8})\end{array}$ & $\begin{array}{c}\text { Cx } \\
(\mathbf{m})\end{array}$ & $\begin{array}{c}\text { CY } \\
(\mathbf{m})\end{array}$ & $\mathbf{R 1}$ (m) & $\mathbf{R 2}$ (m) & $\begin{array}{c}\boldsymbol{\alpha} \\
(\boldsymbol{0})\end{array}$ & $\begin{array}{c}\text { Relative } \\
\text { Rate } \\
\text { (m3/d) }\end{array}$ \\
\hline 3960 & 2.0 & 0. & 59.7 & 66.90 & 0. & 0.059 \\
7560 & 3.4 & 0. & 65.2 & 77.85 & 0. & 0.186 \\
21540 & 12.7 & 0. & 83.0 & 138.80 & 0. & 0.347 \\
60720 & 22.6 & 0. & 89.5 & 236.67 & 0. & 0.560 \\
106200 & 25.5 & 0. & 90.7 & 309.30 & 0. & 0.724 \\
143460 & 26.3 & 0. & 90.9 & 349.66 & 0. & 1.000 \\
360000 & 30.0 & 0. & 92.2 & 691.15 & 0. & 0.000 \\
\hline
\end{tabular}

\section{Example 3 - PDF Model}

The PDF Model was used to demonstrate the utility of the moments in computing the permeability variation within the investigation area during a pumping test.

The geological model of the PDF Model is made up of three facies and was built using the Sisimpdf geostatistical simulation program of the GSLIB Library ${ }^{6}$. The geostatistical properties of the facies together with their petrophysical properties are summarised in Table 4. The corresponding facies map is shown in Figure 8. The well is located in an area containing facies 2 .

\begin{tabular}{|c|c|c|c|c|c|c|}
\hline \multicolumn{7}{|c|}{ Table 4 - PDF Model - FACIES properties } \\
\hline $\begin{array}{c}\text { Facies } \\
\#\end{array}$ & $\begin{array}{c}\text { Proportion } \\
\text { (fraction) }\end{array}$ & $\begin{array}{c}\text { Range } \\
\text { (number } \\
\text { of cells) }\end{array}$ & $\begin{array}{c}\text { Angle } \\
\left.{ }^{\circ}\right)\end{array}$ & $\begin{array}{l}\text { Perm. } \\
(\mathrm{mD})\end{array}$ & $\begin{array}{c}\text { Poro. } \\
\text { (fract.) }\end{array}$ & $\begin{array}{c}\text { Colour } \\
\text { code }\end{array}$ \\
\hline 1 & .750 & 20 & 0 & 30 & .3 & White \\
\hline 2 & .125 & 20 & -45 & 700 & .3 & Grey \\
\hline 3 & .125 & 20 & 45 & 300 & .3 & Black \\
\hline
\end{tabular}

A constant rate pumping test of $100 \mathrm{~m}^{3} / \mathrm{d}$ was simulated for 23.1 days.

The well pressure and its derivative are represented in Figure 9. In this figure the derivative values corresponding to the three facies permeabilities are also shown. These values were computed according to the relationship between the derivative and the permeability. This relationship applies to a stabilised pressure derivative of a drawdown test in a homogeneous infinite reservoir :

$$
\frac{\partial P}{\partial \log (t)}=\frac{\mu Q}{4 \pi h k}
$$

After the end of the well bore storage dominated flow regime $(t>\cong 200 \mathrm{~s})$, the derivative approaches the near well permeability limit $(t \cong 500 \mathrm{~s})$. Afterwards, this derivative shows an increasing apparent permeability which stabilises at $62.8 \mathrm{mD}$ at the end of the test. This value is very close to the model's geometric average permeability $66 \mathrm{mD}$.

\begin{tabular}{|c|c|}
\hline \multicolumn{2}{|c|}{ Table 5 - PDF Model - Main properties } \\
\hline $\begin{array}{l}\text { RESERVOIR SHAPE properties } \\
\text { One layer } 15 \mathrm{~m} \text { thick } \\
\text { Rectangular size (m) }\end{array}$ & $12500 \times 15000$ \\
\hline Facies properties & cf. Table 4 \\
\hline $\begin{array}{l}\text { FIUID properties } \\
\text { Fluid viscosity }(\mathrm{cp}) \\
\text { Volume Factor }\left(\mathrm{m}^{3} \mathrm{st} / \mathrm{m}^{3}\right)\end{array}$ & $\begin{array}{l}1.0 \\
1.0\end{array}$ \\
\hline $\begin{array}{l}\text { WELI properties } \\
\text { Well radius }(\mathrm{cm}) \\
\text { Skin }\end{array}$ & $\begin{array}{l}7.85 \\
-1.5 \\
\end{array}$ \\
\hline $\begin{array}{l}\text { NUMERICAI MODELS properties } \\
\text { Grid blocks }\end{array}$ & $258 \times 308 \times 1$ \\
\hline
\end{tabular}

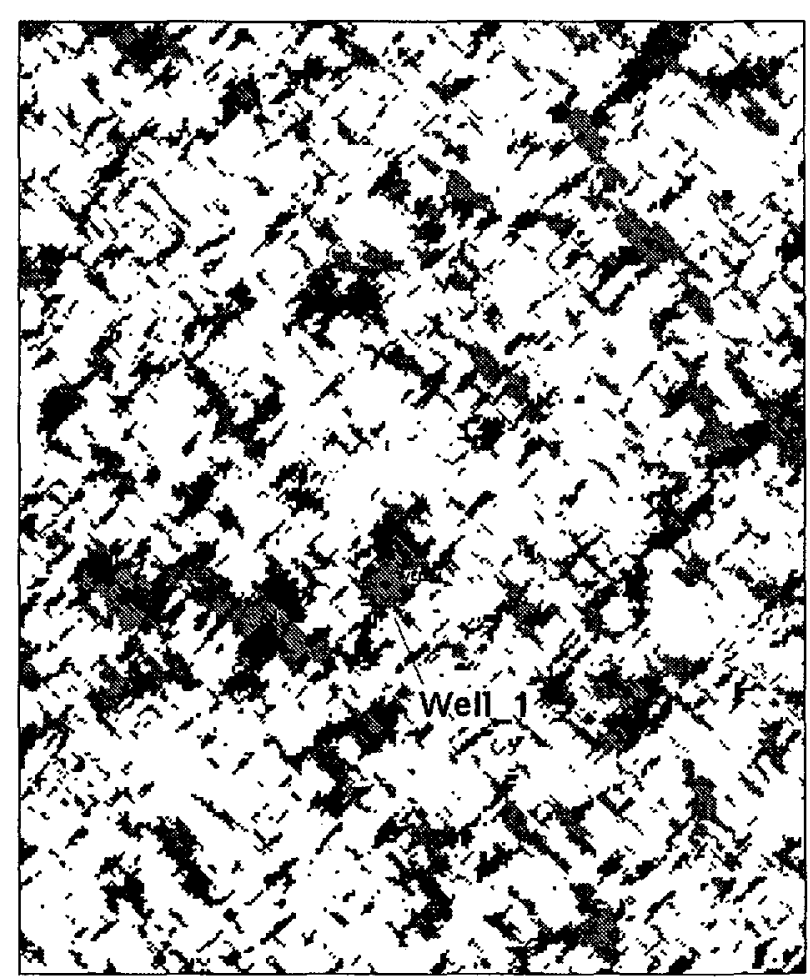

Figure 8 - PDF model - Facies map 
Two different methods were used to derive the apparent permeability :

- The first method is based on the derivation of $\operatorname{Kapp}_{\text {derivative }}(t)$ from the pressure derivative according to relationship (22). The corresponding curve is represented by the plain curve in Figure 10.

- The second method is an extension of the Feitosa' $\mathrm{s}^{7}$ work. At any given time $t$, the reservoir can be split into several concentric ellipses around the ellipse with radii $R I(t)$ and $R 2(t)$ and orientation $\alpha(t)$ resulting from the moment interpretation (Table 6). A series of rings is defined. All the model permeabilities of the grid-blocks lying within one ring are geometrically averaged. The corresponding 1D permeability distribution is then harmonically averaged, and weighted using Oliver's ${ }^{8}$ pressure kernel, to get $\operatorname{Kapp}_{\text {moment }}(t)$ which is represented in Figure 10 and summarised in Table 6.

The comparison between these two apparent permeability evaluations shows that they are quite close to each other. This agreement can be considered a validation of the use of pressure moment interpretation for such analyses.

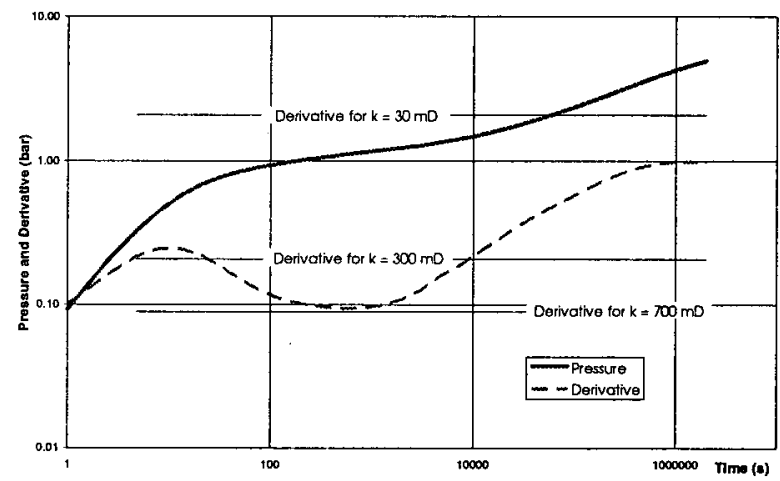

Figure 9 - PDF Model - Pressure and Derivative

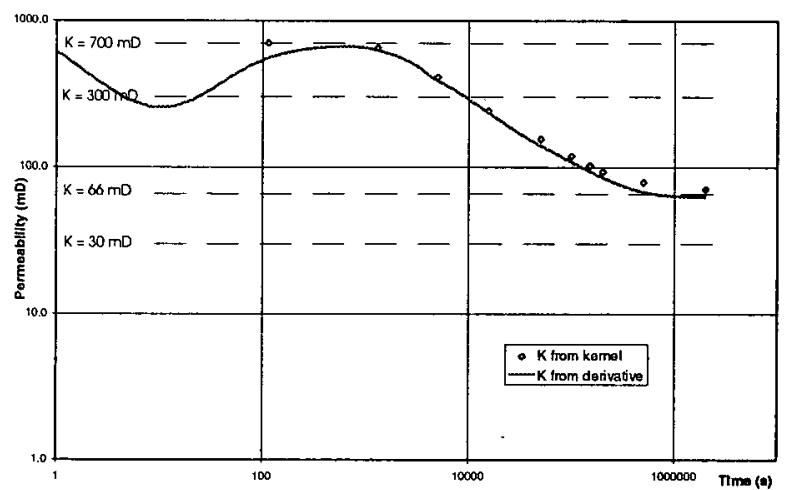

Figure 10 - PDF Model - Apparent Permeability

\begin{tabular}{|c|c|c|c|c|c|}
\hline \multicolumn{6}{|c|}{ Table 6 - PDF Model - Results } \\
\hline $\begin{array}{c}\text { Time } \\
\text { (s) }\end{array}$ & $\begin{array}{l}\mathrm{R} 1 \\
(\mathrm{~m})\end{array}$ & $\begin{array}{l}\mathrm{R} 2 \\
(\mathrm{~m})\end{array}$ & $\begin{array}{c}\alpha \\
\left(^{\circ}\right)\end{array}$ & $\begin{array}{l}\text { Kapp } \\
\text { deriv. } \\
(\mathrm{mD})\end{array}$ & $\begin{array}{c}\text { Kapp } \\
\text { moments } \\
(\mathrm{mD})\end{array}$ \\
\hline$\overline{113}$ & 56 & 56 & $\overline{-27}$ & 553.6 & 700.0 \\
\hline 1311 & 160 & 168 & -22 & 625.9 & 650.0 \\
\hline 5000 & 231 & 262 & -19 & 385.3 & 406.9 \\
\hline 15530 & 308 & 376 & -19 & 233.2 & 2407 \\
\hline 50000 & 424 & 533 & -22 & 139.1 & 154.8 \\
\hline 100000 & 530 & 652 & -27 & 108.1 & 118.5 \\
\hline 150400 & 617 & 742 & -32 & 93.6 & 102.1 \\
\hline 200000 & 691 & 818 & -38 & 85.1 & 92.9 \\
\hline 500000 & 1020 & 1177 & -59 & 67.6 & 78.8 \\
\hline 2000000 & 1937 & 2123 & -79 & 62.8 & 71.2 \\
\hline
\end{tabular}

\section{DECONVOLUTION OF RATE EFFECTS}

\section{Statement of the problem}

The DST Model demonstrated that the rate effects are compounded on the ellipse characteristics during the successive flow periods of a DST. These rate effects must first be deconvoluted before any analysis of the investigation area during the last build up period.

This convolution problem is well-known in the interpretation of multi-rate tests. The build-up pressure used in such analyses is the "pressure difference" between the actual pressure and the drawdown pressure recorded at the end of the last flow period. Any well test analyst would prefer instead to be able to obtain the "differential pressure" as defined in Figure 11.

Actually, two different deconvolution methods were investigated :

- The first method is a brute force method which requires the knowledge of the differential pressure maps at each time of the considered flow period where the moments have to be computed. These maps are obtained by subtracting the two maps originating from the simulation of the two rate histories represented in Figure 11. The previous equations (18), (19) and (20) can then be applied to the differential maps to get the ellipse characteristics.

- The second method is based on the use of the superposition theorem which applies when the well pressure response $P_{w}\left(q_{w} t\right)$ is a linear function of the well rate $q w$ (the case when the permeability and the total compressibility are not pressure dependent) :

$P_{w}\left(q_{w}, t\right)=q_{w} \times G(t)$ 
The well pressure $R(t)$ for any number of constant rates $\left(\mathrm{q}_{1}, \ldots, \mathrm{q}_{\mathrm{n}}\right)$ flow periods $\left(\mathrm{t}_{1}, \ldots, \mathrm{t}_{\mathrm{n}}\right)$ can then be obtained using the superposition theorem:

$$
\begin{aligned}
& R(t)=q_{1} \times G(t)+ \\
& \left(q_{2}-q_{1}\right) \times G\left(t-t_{1}\right)+\ldots \ldots . . \\
& \left(q_{n}-q_{n-1}\right) \times G\left(t-t_{n-1}\right)
\end{aligned}
$$

As the pressure moments are linear functions of the pressure, the superposition theorem can be applied to these moments themselves. You only need to know the pressure moments for any constant rate simulation to be able to compute the moments for any multi-rate test and then to derive the ellipse characteristics.

\section{Example 4 - TC Model}

The TC Model was used to check the validity of the two deconvolution processes presented here.

This model is a one layer representation of a turbiditic channel. The shape of the reservoir was simulated using dead cells (Figure 13) within a rectangular area of $1300 \mathrm{~m} \times 2950 \mathrm{~m}$. The total number of cells is $58 \times 67 \times 1$.

The reservoir thickness is $5 \mathrm{~m}$ at the borders of the channel and thickens to $40 \mathrm{~m}$ toward its main axis. At the well location, the reservoir thickness is $18 \mathrm{~m}$.

The petrophysical properties used are the same as the properties used for the DST Model shown in Table 3.

The flow-rates period of the test are represented in Figure 1.

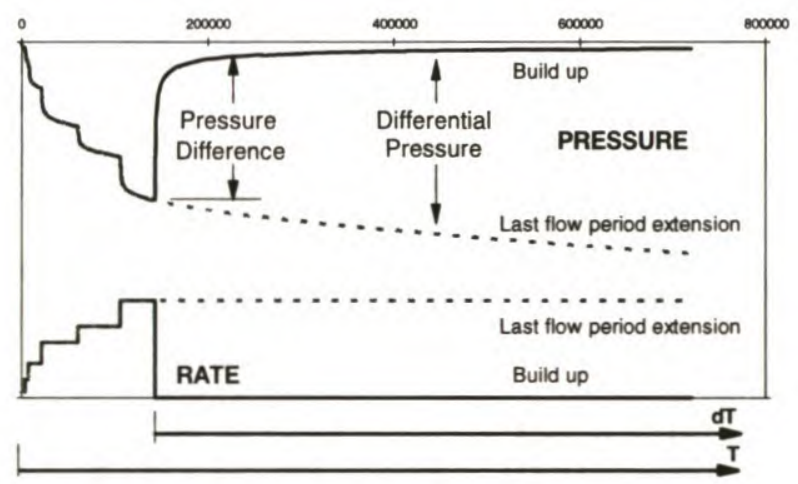

Figure 11 - TC Model - Rates and Pressures

The characteristics of the ellipse for the DST simulation are represented in Figure 12. As expected, the radii increase continuously throughout the test which makes impossible to determine the investigated area during the build-up alone.

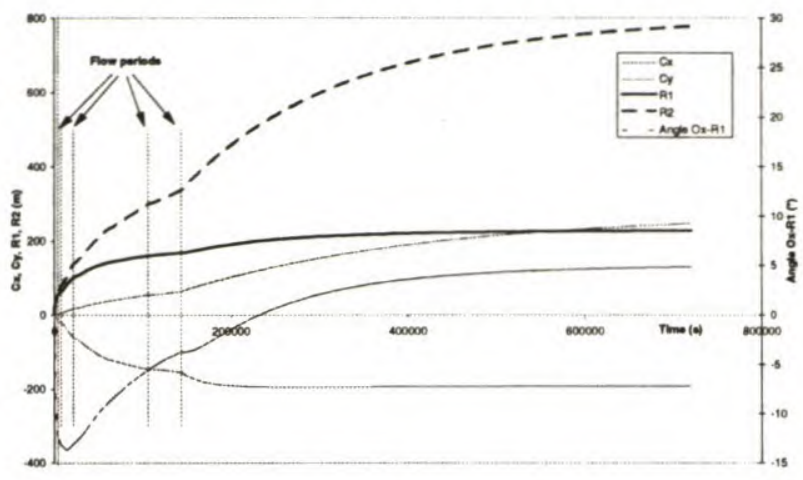

Figure 12- TC Model (Build up) - Ellipse properties versus time

In order to obtain the correct evolution of this investigation area during the build-up period a second simulation was run using the rate history corresponding to the "last flow period extension" of Figure 11. The differential pressure maps were obtained by subtracting the maps originating from the two runs (three iso-contour displays of these maps are shown in Figure 12). The equations (18), (19) and (20) were then applied to 9 recorded differential pressure maps to get the characteristics of the ellipse at the corresponding build-up times. The results of these computations are represented in Figures 13 and 14.

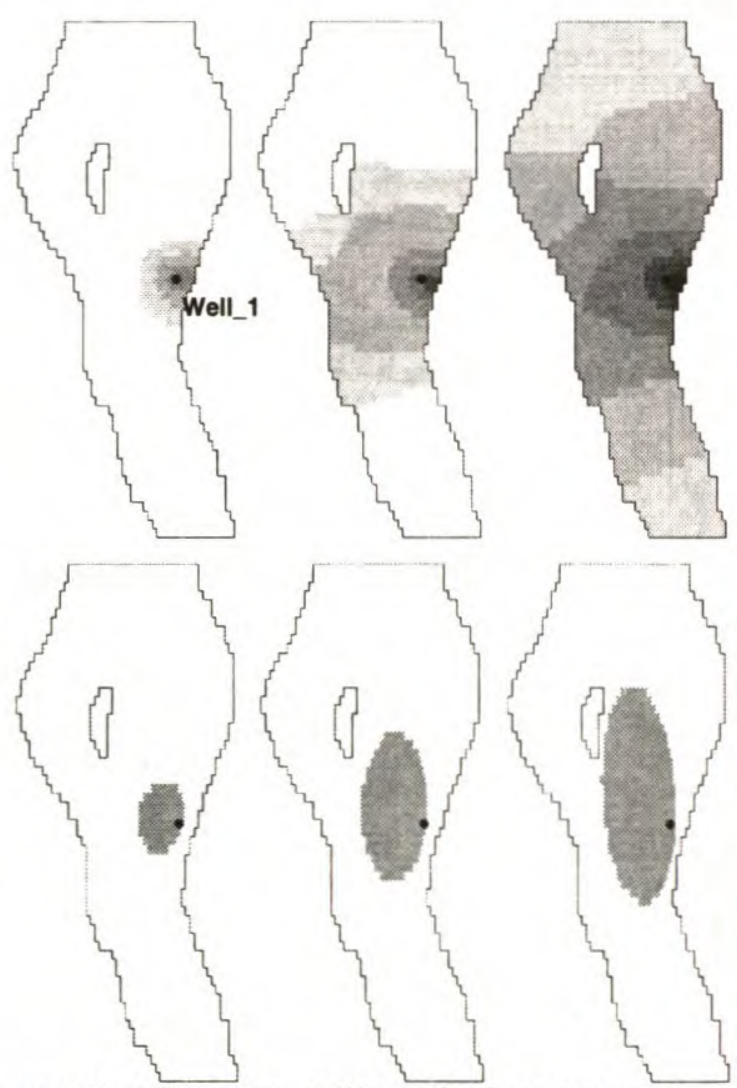

Figure 13 - TC Model - Differential Pressure and Ellipses during Build-up for build-up times 40000 s, 200000 s and at the end of the build-up 
The convolution method proposed was then applied. A constant rate simulation was run for the entire test and the three moments of the differential pressure were computed using the superposition theorem. The results of the ellipse computations, which are also represented in Figure 14, demonstrate that the two methods give the same results. Any one of these methods can be used to deconvolute the rate effects on any flow period of a multirate test.

When the convolution theorem can be applied, the second method is far better. This method requires only one simulation run and gives the ellipse characteristics at any time at a minimal extra cost in term of computer time. In contrast the differential pressure method requires two different simulation runs and is only able to give the ellipse characteristics at specific times where the pressure maps were recorded.

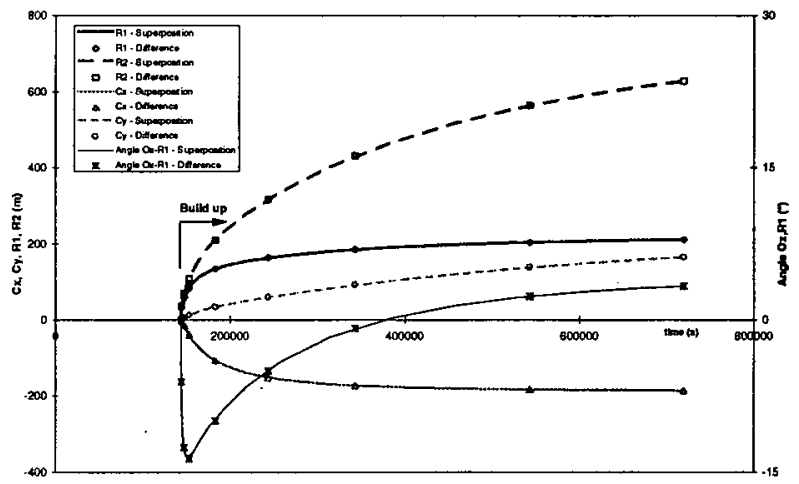

Figure 14 TC - (Differential) - Evolution of Ellipse properties

\section{CONCLUSIONS}

An extension of the use of pressure moments to anisotropic drawdown pressure maps was developed and validated. The ellipses of inertia of the pressure drawdown maps proved to be useful in evaluating the investigation radius and in computing the permeabilitytime relationship during a well test.

Areas other than the interpretation of numerical well tests can also benefit from these results:

- The knowledge of the investigation area provides the means to be able to better design new well tests ;

- The method can be extended to the characterisation of a given geostatistical model through the identification of an equivalent radial permeability distribution around the well.
- The derivation of the investigation area is a key parameter in the constraint of geostatistical images with dynamic data from the well tests ${ }^{9,10,11}$.

\section{NOMENCLATURE}

$\begin{array}{ll}\alpha= & \text { angle } O x, R, \\ c_{l}= & \text { total compressibility, } \mathrm{Lt}^{2} / \mathrm{m}, 1 / \mathrm{bars} \\ \mathrm{Cx}, \mathrm{Cy}= & \text { centre of gravity of ellipse, } \mathrm{L}, \mathrm{m} \\ \Delta x, \Delta y= & \text { grid-block dimension, } \mathrm{L}, \mathrm{m} \\ h= & \text { reservoir thickness, } \mathrm{L}, \mathrm{m} \\ k= & \text { permeability, } \mathrm{L}^{2}, \mathrm{mD} \\ m 0, m 1, m 2= & \text { reduced pressure moments } \\ M 0, M 1, M 2= & \text { pressure moments } \\ P= & \text { pressure, } \mathrm{m} / \mathrm{L} \mathrm{t}^{2}, \mathrm{bar} \\ q= & \text { sink term, } \mathrm{L}^{3} / \mathrm{t} \\ Q= & \text { well flow rate, } \mathrm{L}^{3} / \mathrm{t}, \mathrm{m}^{3} / \mathrm{d} \\ r_{w}= & \text { well radius, } \mathrm{L}, \mathrm{cm} \\ R_{p} R_{2}= & \text { ellipse radii, } \mathrm{L}, \mathrm{m} \\ t= & \text { time, } \mathrm{t} \\ T= & \text { transmissivity, } \mathrm{L}^{2} / \mathrm{t} \\ V_{i}= & \text { grid block volume, } \mathrm{L}^{3}, \mathrm{~m}^{3} \\ w= & \text { weight } \\ \phi= & \text { porosity, fraction } \\ \mu= & \text { fluid viscosity, } \mathrm{m} / \mathrm{Lt}, \mathrm{cp}^{2} \\ \rho= & \text { fluid density, } \mathrm{m} / \mathrm{L}^{3}, \mathrm{~g} / \mathrm{cm}^{3}\end{array}$

Subscripts

$i=\quad$ co-ordinate index

$w=\quad$ well

\section{ACKNOWLEDGEMENTS}

The authors thanks Elf Aquitaine Production, Gaz de France and Institut Français du Pétrole for their permission to publish this paper.

Part of this work has been done within the frame of the HELIOS common research project between Elf and IFP. All participants to this project are thanked for their valuable discussions on all aspects of the work.

\section{REFERENCES}

1. Van Poolen, H.K.:" Radius of Drainage and Stabilisation Time Equations". Oil and Gas Journal, September 14, 1964, p. 138-146.

2. Lee, J.: " Well Testing ". SPE Textbook Series. Volume 1.

3. Muskat, M.: " Physical Principles of Oil Production ". Mc Graw Hill Book Co., Inc., New York 1949. 
4. Nœtinger, B.: "A Pressure Moment Approach For Helping Pressure Transient Analysis In Complex Heterogeneous Reservoirs". SPE 26466. SPE Annual Conference and Exhibition, Houston, Texas, October 1993, 521-529

5. Blanc, G. et al.: " Numerical Well-tests Simulation in Heterogeneous Reservoirs ". Poster presented at AAPG, Nice 95.

6. Deutsch, C.V., Journel, A.G.: "GSLIB Geostatistical Software Library and User's Guide". Oxford University Press, 1992.

7. Feitosa, G..S.. "Well Test Analysis for Heterogeneous Reservoirs". PhD dissertation, University of Tulsa, (1993).

8. Oliver, D. S.: "The averaging process in permeability estimation from well-test data". SPE Formation Evaluation, 5, 319-324, 1990.

9. Blanc, G. et al. : "Building Geostatistical Models Constrained by Dynamic Data". SPE 35478 presented at the SPE/NPF European Conference held in Stavanger, Norway, 16-17 April 1996.

10. Haas, A., Nœtinger, B.: "Stochastic Reservoir Modelling Constrained by Well Tests Permeabilities". To be presented at 5th International Geostatistic Congress, Wollongong' 96, September 22-27, 1996.

11. Nœtinger, B. and Haas, A,: "Permeability Averaging for Well Tests in 3D Stochastic Reservoir Models ". SPE 36653 to be presented at the 1996 SPE Annual Technical Conference and Exhibition held in Denver, Colorado, 6-9 October 1996. 